\title{
Orofarenks Kanserlerinde Boyun Metastazlarına Yaklaşım
}

\section{Approach to Neck Metastases in Oropharyngeal Cancers}

\section{İsrafil ORHAN ${ }^{1}$, Nagihan BİLAL ${ }^{1}$}

${ }^{1}$ Doç. Dr. Kahramanmaraş Sütçü İmam Üniversitesi Tıp Fakültesi Kulak Burun ve Boğaz Hastalıkları Anabilim Dalı, KAHRAMANMARAŞ

Öz

Orofarenks kanserlerinde prognozu belirleyen en önemli parametrelerden biri boyun metastazlarıdır. Orofaringeal tümörlerin çoğunda okült metastaz olasılığının \% 20'nin üzerinde olması nedeni ile genellikle boynun elektif olarak tedavisi önerilmektedir. Tedavi seçenekleri cerrahi veya radyoterapi olabilir. İleri evre orofaringeal karsinomlarda ise tedavi seçenekleri boyun diseksiyonu ve adjuvan onkolojik tedavilerle birlikte transoral cerrahi ve kemoradyoterapiyi içermektedir. Bu makalede orofarengeal karsinomların boyun metastaz oranlarını ve bu metastazlara yaklaşımı gözden geçirmeyi amaçladık.

Anahtar Kelimeler: Orofarengeal kanser, boyun metastazi, tedavi yaklaşımları

\section{GİRIŞ}

Orofaringeal kanserlerin prognozunu belirleyen faktörlerin başında metastatik servikal lenf nodu varlığı gelmektedir. Orofaringeal karsinomlarda nodal metastaz riski yüksek olduğu için boyun N0 olsa dahi elektif olarak tedavi edilmelidir. Tedavi seçenekleri cerrahi veya radyoterapi olabilir $(1,2)$.

Boyuna metastazda önemli faktörler arasında, tümörün HPV ile olan ilişkisi, diferansiasyonu, T evresi ve lokalizasyonu sayılabilir (2). Lokalizasyon açısından orofarenks cerrahi anatomide çeşitli bölgelere ayrılır; dil kökü, yumuşak damak, tonsiller ve posterior farengeal duvar. Bu bölgelerin ayrı ayrı ele alınarak lenfatik drenajlarını değerlendirmek, hastalığın yayılımının daha iyi anlaşılmasında ve boynun tedavisinde daha yardımcı olacaktır. Anteriorda sirkumvallat papilla, laterallerde glossopalatin sulkus ve inferiorda vallekula ile sınırlı alan dil kökünün sınırlarını oluşturmaktadır. Dil kökünün lenfatik drenajı üst 2. ve 3. juguler lenfatik zincire ve sıklıkla bilateral olur. Yumuşak damağın lenfatik drenajı üç farklı bölgeye olmaktadır. Medial kısmın lenfatik drenajı seviye 3 juguler zincire, lateral kısımlar retrofarengeal lenfatiklere, sert damağa yakın anterior kısım ise submental ve submandibular lenf nodlarına drene olur. Orta kısmın drenajı sıklıkla bilateral olmaktadır. Üstte yumuşak damak seviyesinden aşağıda epiglot seviyesine kadar uzanan posterior faringeal duvarın lenfatik drenajı bilateral üst juguler zincire olurken, orta juguler zincir ve posterior servikal üçgene de drenajı görülür. Tonsillerin lenfatik drenajı ise öncelikli olarak lateral retrofarengeal nodlara ve seviye 3 juguler zincire drene olur. Bunun yanında alt juguler nodlara ve posterior servikal üçgene yayılım da sık görülür (3).

\section{Orofarenks Kanserlerinde Boynun Klinik}

$\begin{array}{ll}\text { İletişim: } & \begin{array}{l}\text { Dr. İsrafil Orhan, KSÜ Tip Fakültesi KBB AD, Kahra- } \\ \text { manmaraş }\end{array} \\ \text { DOI: } & \mathbf{1 0 . 1 7 5 1 7 / k s u t f d . 4 9 6 4 9 6}\end{array}$

\section{Abstract}

Cervical lymph node metastasis is one of the most important prognostic parameter in oropharyngeal carsinomas. Most oropharyngeal tumors have occult metastases rates exceeding $20 \%$, and elective treatment of the neck is generally recommended. Treatment options may be surgery or radiotherapy. Options for treatment of advanced oropharyngeal carsinomas include chemoradiotherapy or transoral surgery with neck disection and adjuvant oncological treatment. In this article, we aimed to review the rates of neck metastasis and the approach of these metastases to oropharyngeal carcinomas.

Key Words: Oropharyngeal cancer, neck metastasis, treatment approaches

\section{Değerlendirilmesi}

Metastatik lenf bezlerinin değerlendirilmesinde tek başına palpasyonun yeterli olmadığı ve sadece palpasyon ile yapılan boyun değerlendirmelerinde okült metastazların \% 30 dolayında olduğu bilinmektedir $(4,5)$. Fizik muayene ile boynun değerlendirilmesi, lenfatik metastaz tanısı açısından düşük sensitivite ve spesifiteye sahiptir. Bu nedenle en önemli prognostik faktör olan boyun evrelendirilmesinde bilgisayarlı tomografi (BT) veya manyetik rezonans görüntüleme (MR) tetkiklerinden en az birinin kullanılması önerilmektedir (6, 7). $\mathrm{Bu}$ görüntüleme yöntemleriyle lenf bezi metastazlarının değerlendirilmesinde, lenf bezinin boyutu ve longitudinal boyutunun transvers boyutuna oranı en sik kullanılan kriterlerdir. Lenf bezlerinin şekli, kontrastlanma özellikleri ve konglomerasyon göstermesi ise metastaz değerlendirmesinde kullanılan ikincil kriterlerdir (8). Ancak günümüz kesitsel görüntüleme olanakları ile bile belirgin olarak büyümemiş, santral nekroz ve ekstrakapsüler invazyon göstermeyen metastatik lenf nodlarının, reaktif lenf nodlarından ayrılması güçlük arz etmektedir. Görüntüleme yöntemlerinden USG, MR, BT ve PET-BT baş boyun tümörlerinin evrelemesinde kullanılsa da lenf nodunun tutulmuş olduğunu gösteren tek metod cerrahi olarak çıkarılan lenf nodunun histopatolojik olarak değerlendirilmesidir $(9,10)$. Erken evre tümörlerde sentinal lenf nodu biyopsisi lenfatik direnaj patterninin belirlenmesinde kullanılabilir (4, 11-14).

\section{Orofarenks Kanserlerinde Metastatik Lenf Nodlarının Boyundaki Dağılımı}

Boyuna metastazda önemli faktörler arasında, tümörün HPV ile olan ilişkisi, diferansiasyonu, T evresi ve lokalizasyonu sayılabilir $(2,15,16)$. Bu faktörler aynı zamanda boyuna olan metastazın unilateral veya bilateral olmasını da etkilemektedir.

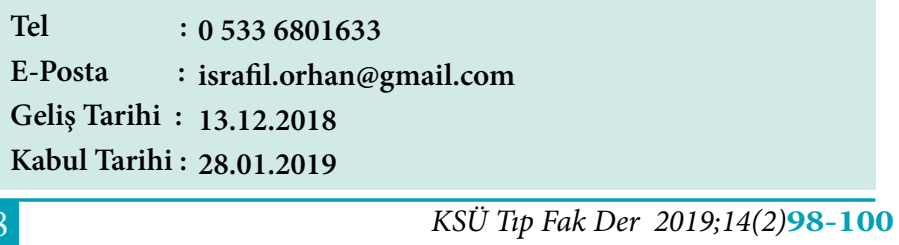


HPV pozitif hastalık HPV negatif hastalığa göre daha yüksek oranda boyun metastazı yapar ve $\mathrm{N}$ evresi daha ileri düzeydedir. Yine HPV pozitif hastalık daha yüksek oranda kontralateral veya bilateral boyun metastazı yapar (16-18). Tümör diferansiasyonu boyun metastazını belirleyen önemli faktörlerden biri olup kötü diferansiasyonu olan tümörler iki kat fazla kontralateral veya bilateral boyun metastazı yapar $(1,19)$. Klinik T evresi yükseldikçe tümör kütlesi büyümekte, medial yapılara yaklaşmakta ve boyun metastaz riski yükselmektedir. T4 tümör T1 tümöre göre yedi kat, T3 tümör T1 tümöre göre 5 kat, T2 tümör T1 tümöre göre 2 kat artmış kontralateral veya bilateral boyun metastaz oranına sahiptir ( 1 , 20-22). Tümör invazyon derinliği ve büyüklüğü ile boyun lenf nodu mikrometastazı arasındaki ilişkiyi araştıran bir çalışmada tümör büyüklüğü $25 \mathrm{~mm}$ ve invazyon derinliği $10 \mathrm{~mm}$ olan tüm tümörlerde mikrometastaza rastlanmıştır (23-25).

Lokalizasyon olarak lateralize orofaringeal karsinomlarda kontralateral boyun metastaz oranı düşüktür. Ancak özellikle dil kökü tümörlerinde ve medial yapıları tutmuş ileri evre tümörlerde bilateral boyun metastazı sıktır. Erken evre dil kökü tümörlerinin \%20'sinde ilk tanı anında bilateral boyun tutulumu ortaya konmuştur (26). Aynı şekilde T1-T2 palatal orofarengeal kanserlerin \%20'sinde boyun tutulumu varken, T3 ve T4 tümörlerde \%60-70 oranında rejyonel metastaz mevcuttur (26). Orta hattı geçmiş olan posterior farengeal duvar tümörlerinde yüksek oranda bilateral nodal tutulum görülürken, tonsil tümörlerinin \%66-76'sında jugulodigastrik lenf nodu tutulumu mevcuttur $(27,28)$.

Yapılan çalışmalarda klinik olarak N0 olan boyunlarda yapılan elektif boyun diseksiyonu sonucu metastatik lenf nodlarının I. bölgede \% 0-\% 7, II. bölgede \% 25-\% 68, III. bölgede \% 19-\% 41 ve V. bölgede \% 1-\% 12 oranında olduğu tespit edilmiştir. Klinik olarak $\mathrm{N}+$ olan boyunlarda yapılan terapötik boyun diseksiyonu sonucu ise I. bölgenin \% 0-\% 15, II. bölgenin \% 37-\% 83, III. bölgenin \% 11-\% 45, IV. bölgenin \% 7-\% 37 ve V. bölgenin \% 0-\% 10 oranında tutulduğu rapor edilmiştir $(29,30)$. Lim ve ark. yaptıkları bir çalışmada, N0 boyna yönelik yapılan 104 boyun diseksiyon spesmenini gözden geçirdiklerini ve seviye IV'de \% 37 oranında metastaz saptadıklarını, seviye I'de ise \% 10 oranında metastaz tespit ettiklerini bildirmişlerdir (15). Bu nedenle seviye II-IV’ün alınmasının daha doğru olacağını bildirmişlerdir. Benzer bir çalışmada Shah orofarengel kanser nedeni ile yapılmış 1119 radikal boyun diseksiyonu spesmenini incelemiş ve en sık yayılımın seviye II,III ve IV'e olduğunu ortaya koymuştur (29). Yine Karolina ve ark. yaptığı bir çalışmada en sık metastazın II. bölgede görüldüğü, dil kökü tümörlerinde ve T4 tümörlerde metastazın bilateral olduğu görülmüştür. Sonuç olarak ise yapilacak elektif boyun diseksiyonunun en az IIA-B ve III. bölgeyi kapsaması gerektiği, terapötik boyun diseksiyonunun ise mutlaka IIA-B, III ve IV. bölgeyi içermesi gerektiği vurgulanmıştır (17).

\section{Tedavisi}

Orofarenks Kanserlerinde Boyun Metastazlarının

Son yllarda orofarengeal kanserlerin tedavisinde transoral robotik cerrahi veya klasik açık cerrahi prosedürlerin yanında kombine radyoterapi ve kemoterapi de ilk tedavi seçeneği olarak tercih edilebilmektedir. Boyuna uygulanacak tedavinin tipi primer tümöre, yerleşim yerine, evresine ve boynun tutulumuna göre belirlenir. Orofarengeal kanserlerde okkült metastaz oranının \% 20'den fazla olmasından dolayı
N0 boyunlarda rejyonel nodal tedavi uygulanmalıdır (26). Bu hastalar için en uygun prosedür selektif boyun diseksiyonudur. Lateral boyun diseksiyonu önerilen boyun diseksiyonu tipidir. $\mathrm{Bu}$ hastalarda tedavi seçenekleri cerrahi veya radyoterapi olabilir $(1,2)$. İleri nodal hastalıkta (N2veya N3) ise boyun diseksiyonu ve ardından kemoradyoterapi ile kombine tedavi tercih edilebilir $(2,9)$. Özellikle cerrahi sınır pozitifliği ve ekstrakapsüler yayılım varsa kombine kemoradyoterapi göz önünde bulundurulmalıdır. Eğer ekstrakapsüler yayılım yoksa tek başına radyoterapi ile tedavi edilebilir (9).

\section{KAYNAKLAR}

1. Kato MG, Ellis MA, Nguyen SA, Terry AD. Predictors of contralateral-bilateral nodal disease in oropharyngeal cancer: A National Cancer Data Base Study. Head Neck 2018; 40: 338-48.

2. Gottumukkala S, Pham NL, Sumer B, Myers L, Truelson J, Nezdi L, et al. Risk of contralateral nodal failure following ipsilateral IMRT for node-positive tonsillar cancer. Oral Oncol 2017; 75: 35-8.

3. Derin AT, Yaprak N. Orofarenks tümörlerinde boyun diseksiyonları. Turkiye Klinikleri J E. N. T. Special Topics 2017; 10: 55-8.

4. İkiz AÖ, Polack BD. Baş boyun kanserlerinde sentinal lenf nodu sintigrafisi ve biyopsisi. Nuclear Medicine Seminars 2017; 3: 121-8.

5. Köhler HF, Franzi SA, Soares FA, Torloni H, Kowalski LP. Distribution of metastatic nodes in N0-1 patients with tonsillar squamous cell carcinoma and its implications for selective neck dissection. Turk Arch Otorhinolaryngol. 2018; 56: 139-144.

6. Tsujikawa T, Narita N, Kanno M, Takabayashi T, Fujieda $\mathrm{S}$, Okazawa $\mathrm{H}$. Role of PET/MRI in oral cavity and oropharyngeal cancers based on the 8 th edition of the AJCC cancer staging system: a pictorial essay. Ann Nucl Med 2018; 32: 239-49.

7. Riese CGU, Karstadt JA, Schramm A, Guleryuz S, Dressel G, Lorenz KJ. Validity of sentinel node biopsy in early oral and oropharyngeal carcinoma. J Craniomaxillofac Surg 2018; 46: 1748-52.

8. Mack MG, Rieger J, Baghi M, Bisdas S, Thomas J V. Cervical lymph nodes. Eur J Radiol 2008; 66: 493-500.

9. Fox HR, Robson A, Cocks H, Meikle D, Kelly C, Goranova $\mathrm{R}$, et al. Contralateral neck metastases in lateralised, resectable advanced stage oropharyngeal squamous cell carcinoma-Results of 57 patients undergoing bilateral selective neck dissection. Clin Otolaryngol 2018; 43: 79294.

10. Rassekh CH, O’Malley BW Jr, Bewley AF, Montone KT, Livolsi VA, Weinstein WS. Feasibility and relevance of level I substation node counts in oropharyngeal carcinoma. Head Neck. 2016; 38: 1194200.

11. Taylor RJ, Wahl RL, Sharma PK. Sentinel node localization in oral cavity and oropharynx squamous cell cancer. Arch Otolaryngol Head Neck Surg. 2001;127: 970-4.

12. Pitman KT, Johnson JT, Brown ML, Myers EN. Sentinel 
lymph node biopsy in head and neck squamous cell carcinoma. Laryngoscope 2002; 112: 2101-13.

13. Calabrese L, Bruschini R, Ansarin M, Giugliano G, Cicco De C, Lonna F, et al. Role of sentinel lymph node biopsy in oral cancer. Acta Otorhinolaryngol Ital. 2006; 26: 345-9.

14. Zitsch RP, Todd DW, Renner GJ, Singh A. Intraoperative radiolymphoscintigraphy for detection of occult nodal metastasis in patients with head and neck squamous cell carcinoma. Otolaryngol Head Neck Surg. 2000; 122: 6626.

15. Lim YC, Koo BS, Lee JS, Lim JY, Choi EC. Distributions of cervical lymph node metastases in oropharyngeal carcinoma: therapeutic implications for the N0 neck. Laryngoscope 2006 Jul; 116: 1148-52.

16. Tritter AG, Mehta V, Samuelson M, deGravelle G, Ma $\mathrm{X}$, Medlin-Moore $\mathrm{T}$, et al. Incidence of contralateralbilateral nodes in the human papillomavirus era. Laryngoscope. 2017;127: 1328-33.

17. Plonowska KA, Strohl MP, Wang SJ, Ha PK, George JR, Heaton CM, et al. Human Papillomavirus-Associated Oropharyngeal Cancer: Patterns of Nodal Disease. Otolaryngol Head Neck Surg 2018; 2: 1-8.

18. Stenmark MH, Shumway D, Guo C, Vainshtein J, Mierzwa $\mathrm{M}$, Jagsi $\mathrm{R}$, et al. Influence of human papillomavirus on the clinical presentation of oropharyngeal carcinoma in the United States. Laryngoscope 2017; 127: 2270-78.

19. 19. Jacobi C, Rauch J, Hagemann J, Lautz T, Reiter $\mathrm{M}$, Baumeister P. Prognostic value of the lymph node ratio in oropharyngeal carcinoma stratified for HPV-status. Eur Arch Otorhinolaryngol 2018; 275: 515-24.

20. Sood AJ, McIlwain W, O'Connell B, Nguyen S, Houlton JJ, Day T. The association between T-stage and clinical nodal metastasis In HPV-positive oropharyngeal cancer. Am J Otolaryngol 2014; 35: 463-8.

21. Lim YC, Lee SY, Lim JY, Hyang AS, Jin SL, Bon SK, et al. Management of contralateral N0 neck in tonsillar squamous cell carcinoma. Laryngoscope. 2005; 115: 16725.
22. Lee DJ, Kwon MJ, Nam ES, Kwon JH, Kim JH, Rho YS, et al. Histopathologic predictors of lymph node metastasis and prognosis in tonsillar squamous cell carcinoma. Korean J Pathol 2013; 47: 203-10.

23. Cho JH, Lee YS, Sun DI, Kim MS, Cho KJ, Narm IC, et al. Prognostic impact of lymph node micrometastasis in oral and oropharyngeal squamous cell carcinomas. Head Neck 2016; 38; 1777-82.

24. Spiro RH, Huvos AG, Wong GY, Spiro JD, Gnecco CA, Strong EW. Predictive value of tumor thickness in squamous carcinoma confined to the tongue and floor of the mouth. Am J Surg 1986; 152: 345-50.

25. Carrau RL, Barnes EL, Snyderman CH, Petruzzelli G, Kachman K, Rueger R, et al. Tumor angiogenesis as a predictor of tumor aggressiveness and metastatic potential in squamous cell carcinoma of the head and neck. Invasion Metastasis 1995; 15: 197-202.

26. Cohan DM, Popat S, Kaplan SE, Rigual N, Loree T, Hicks WL, et al. Oropharyngeal cancer: current understanding and management. Curr Opin Otolaryngol Head Neck Surg 2009; 17: 88-94.

27. Osborne RF, Brown JJ. Carcinoma of the oral pharynx: an analysis of subsite treatment heterogeneity. Surg Oncol Clin N Am 2004; 13: 71-80.

28. Lin DT, Cohen SM, Coppit GL, Burkey BB. Squamous cell carcinoma of the oropharynx and hypopharynx. Otolaryngol Clin North Am 2005; 38: 59-74.

29. Shah JP. Patterns of cervical lymph node metastasis from squamous carcinomas of the upper aerodigestive tract. Am J Surg 1990; 160: 405-9.

30. Gross BC, Olsen SM, Lewis JE, Jan L. K, Eric J. M, Price DL. Level IIB lymph node metastasis in oropharyngeal squamous cell carcinoma. Laryngoscope 2013; 123: 27005. 